\title{
Retinoic acid modulates intrahippocampal levels of corticosterone in middle-aged mice: consequences on hippocampal plasticity and contextual memory
}

\section{Damien Bonhomme ${ }^{1,2}$, Véronique Pallet ${ }^{1,2}$, Gaelle Dominguez ${ }^{3,4}$, Laure Servant ${ }^{1,2}$, Nadia Henkous ${ }^{3}$, Pauline Lafenêtre ${ }^{1,2}$, Paul Higueret ${ }^{1,2}$, Daniel Béracochéa ${ }^{3}$ and Katia Touyarot ${ }^{1,2}$ *}

${ }^{1}$ INRA, Nutrition et Neurobiologie Intégrée (NutriNeuro), UMR 1286, Bordeaux, France

2 Université de Bordeaux, Nutrition et Neurobiologie Intégrée (NutriNeuro), UMR 1286, Bordeaux, France

${ }^{3}$ CNRS, Intititut de Neurosciences Cognitives et Intégratives d'Aquitaine, UMR 5287, Talence, France

${ }^{4}$ INSERM, U-930, Université François Rabelais, Tours, France

Edited by:

Emil C. Toescu, Birmingham

University, UK

Reviewed by:

Uwe-Karsten Hanisch, University of Göttingen, Germany

Ashok Kumar, University of Florida, USA

\section{*Correspondence:}

Katia Touyarot, INRA, Nutrition et Neurobiologie Intégrée (NutriNeuro), UMR 1286, 146 rue Léo Saignat,

F-33000 Bordeaux, France

e-mail: katia.touyarot@enscbp.fr
It is now established that vitamin A and its derivatives, retinoic acid (RA), are required for cognitive functions in adulthood. RA hyposignaling and hyperactivity of glucocorticoid (GC) pathway appear concomitantly during aging and would contribute to the deterioration of hippocampal synaptic plasticity and functions. Furthermore, recent data have evidenced counteracting effects of retinoids on GC signaling pathway. In the present study, we addressed the following issue: whether the stimulation of RA pathway could modulate intrahippocampal corticosterone (CORT) levels in middle-aged mice and thereby impact on hippocampal plasticity and cognitive functions. We firstly investigated the effects of vitamin A supplementation and RA treatment in middle-aged mice, on contextual serial discrimination task, a paradigm which allows the detection of early signs of age-related hippocampal-dependent memory dysfunction. We then measured intrahippocampal CORT concentrations by microdialysis before and after a novelty-induced stress. Our results show that both RA treatment and vitamin A supplementation improve "episodic-like" memory in middle-aged mice but RA treatment appears to be more efficient. Moreover, we show that the beneficial effect of RA on memory is associated to an increase in hippocampal PSD-95 expression. In addition, intrahippocampal CORT levels are reduced after novelty-induced stress in RA-treated animals. This effect cannot be related to a modulation of hippocampal $11 \beta-H S D 1$ expression. Interestingly, RA treatment induces a modulation of RA receptors RAR $\alpha$ and RAR $\beta$ expression in middle-aged mice, a finding which has been correlated with the amplitude of intrahippocampal CORT levels after novelty-induced stress. Taken together, our results suggest that the preventive action of RA treatment on age-related memory deficits in middle-aged mice could be, at least in part, due to an inhibitory effect of retinoids on GC activity.

\section{Keywords: vitamin A, retinoic acid, corticosterone, memory, hippocampal plasticity}

\section{INTRODUCTION}

Vitamin A, through its active metabolite retinoic acid (RA), plays a key role in cognitive functions and more specifically in hippocampus-dependent memory (Lane and Bailey, 2005; McCaffery et al., 2006; Olson and Mello, 2010). Hippocampal function in memory is dependent on plastic changes in synaptic strength, numbers of synapses and neurons, all of which can be modulated by RA (McCaffery et al., 2006). RA regulates gene expression including plasticity-related genes through binding to specific nuclear receptors: RA receptors (RARs) or retinoic X receptors (RXRs; Marill et al., 2003). When the RARs are functionally removed by mutation in mice, deficits both in long-term potentiation and in hippocampal-dependent memory tasks are observed (Chiang et al., 1998; Wietrzych et al., 2005). These deleterious effects have been also evidenced by using the vitamin A deficiency (VAD) model in rats and mice, a nutritional approach leading to a specific hyposignaling of RA signaling pathway (Cocco et al., 2002; Etchamendy et al., 2003; Bonnet et al., 2008). The disruption of retinoid signaling pathway that result from a hypoexpression of some retinoid receptors in target tissues including the hippocampus, occurs naturally during aging in rodents and humans (Enderlin et al., 1997; Etchamendy et al., 2001; Feart et al., 2005; Mingaud et al., 2008; Touyarot et al., 2013). Moreover, it is well established that this RA hyposignaling contributes to the deterioration of hippocampal plasticity and memory processes during aging and these deleterious effects could be reversed by a vitamin A supplementation or RA treatment (Etchamendy et al., 2001; Mingaud etal., 2008; Touyarot et al., 2013).

Although the involvement of retinoids in the modulation of hippocampal plasticity and functions has been well described in aged rodents, molecular mechanisms underlying 
these effects remain unclear. The hippocampus is a prime target for glucocorticoids (GCs) which bind to abundant mineralocorticoid and GC receptors (MRs and GRs, respectively), known to be involved in the control of hippocampal plasticity and functions (Oitzl and de Kloet, 1992). During aging, hyposignaling of vitamin A pathway occurs concomitantly with hyperactivity of GC pathway leading to excess plasma levels of GCs [cortisol for humans and corticosterone (CORT) for rodents; Born et al., 1995; Tronche et al., 2010] probably due to alterations in the regulation of hypothalamic-pituitary-adrenal (HPA) axis (Mizoguchi et al., 2009). However, although elevated levels of plasma CORT have been largely hypothesized to contribute to age-related memory decline (Cameron and Gould, 1994; Lupien et al., 1998; Yau and Seckl, 2012), few studies focus on the measurement of intrahippocampal CORT levels in aged rodents in relation to memory retrieval performance. Interestingly, it has been recently shown that stress-induced intrahippocampal CORT rise in middle-aged rats was associated with memory impairments in a hippocampaldependent memory task (Chauveau et al., 2009b) that has been previously shown to be affected in middle-aged mice (Celerier et al., 2004; Beracochea et al., 2008a,b; Chauveau et al., 2009a,b; Pierard et al., 2009; Tronche et al., 2010). The magnitude of intracellular CORT action in the rodent hippocampus is thought to be determined by the hippocampal activity of $11 \beta$-hydroxysteroid dehydrogenase type 1 (11 $\beta$-HSD1), an enzyme that regenerates active CORT within cells, but also by free CORT circulating in blood and delivered to the brain (Seckl, 1997). Thus, both the hyperactivity of hippocampal $11 \beta$-HSD1 and the alterations of HPA axis leading to elevated plasma CORT, have been correlated with impairments in hippocampal-dependent memory tasks during aging (Yau etal., 2001; Holmes et al., 2010; Yau and Seckl, 2012).

While the antagonism between GCs and RA pathways has been suggested in few studies using different cell types (Paez-Pereda et al., 2001; Aubry and Odermatt, 2009; Brossaud et al., 2013), no study has scrutinized the regulation of GCs activity by retinoids and its impact on cognitive functions in aged animals. Interestingly, inhibitory effects of RA and vitamin A supplementation have been evidenced on the expression and the activity of $11 \beta$ HSD1, in differentiated C2C12 myotubes (Aubry and Odermatt, 2009) and in obese rats liver (Sakamuri et al., 2011). Finally, it has been recently evidenced an increased HPA axis activity in basal and stress conditions associated with an up-regulation of the hippocampal expression of $11 \beta$-HSD1 in vitamin A deficient LOU/C rats, which have been normalized by RA treatment (Arvy et al., 2013).

Altogether, these data suggested counteracting effects between RA and GCs pathways. In the present study, we addressed whether the stimulation of RA pathway could modulate intrahippocampal CORT levels in middle-aged mice and thereby modify hippocampal plasticity and cognitive functions. We first compared the effects of vitamin A supplementation (20 IU/g retinol, 2 months) and RA treatment $(150 \mu \mathrm{g} / \mathrm{kg}, 5$ days $)$ on memory retrieval of the contextual serial discrimination (CSD) task in middle-aged mice. Thus, we show that short-term RA treatment in middle-aged mice induced an improvement on memory retrieval associated with an increased hippocampal PSD-95 (postsynaptic scaffolding protein
$95 \mathrm{kDa}$ ) mRNA expression, used as a marker of synaptic plasticity. Hence, we measured intrahippocampal CORT concentrations (by microdialysis), in basal conditions and after CSD box-induced stress. We demonstrated for the first time that RA treatment significantly decreased and delayed the stress-induced increase of hippocampal CORT levels observed in middle-aged mice without any effect on basal concentration. Therefore, our results strengthened the hypothesis of a close relationship between vitamin A status and GCs-induced cognitive impairments in middle-aged mice. Thus, acting on vitamin A status could be a good strategy to prevent excess GCs-induced cognitive decline occurring with aging.

\section{MATERIALS AND METHODS ANIMALS}

Middle-aged (Mid-age) C57BL/6 Jico mice (12-month-old) were purchased from Janvier (Le Genest-Saint-Isle, France). They were housed in a collective cage in a room with a constant airflow system, controlled temperature $\left(21-23^{\circ} \mathrm{C}\right)$, and a $12-\mathrm{h}$ light/dark cycle. Mice were granted ad libitum access to food and water and were randomly divided into two experimental groups. One group $(n=22)$ was fed with a control diet containing $5 \mathrm{IU}$ retinol/g or a vitamin A-enriched diet containing $20 \mathrm{IU}$ retinol/g during 2 months (INRA, Jouy-en-Josas). The second group $(n=39)$ was fed with a control diet containing $5 \mathrm{IU}$ retinol/g (INRA, Jouy-en-Josas) during 2 months and received subcutaneous injections of RA or vehicle. One week prior to the experiments, all animals were individually housed until sacrifice. Mice were handled and deprived during this period: all subjects were daily weighed in order to maintain $90 \%$ of their ad libitum body weight throughout the behavioral study. All experiments were performed in accordance with the European Communities Council Directives (86/609/EEC) and the French National Committee (87/848) recommendations, and have been approved by the Animal Care and Use Committee of Bordeaux under the N50120169-A.

\section{DIET}

A first group of middle-aged mice (Mid-age, $n=12$ ) was fed with a control diet containing $5 \mathrm{IU}$ retinol/g (INRA, Jouy-en-Josas) during 2 months. The second half (Mid-age + Vitamin A, $n=10$ ) received the vitamin A-enriched diet (20 IU retinol/g) during the same period. The composition of the control diet was the same as the vitamin A-enriched diet, except for retinol content. The $20 \mathrm{IU}$ diet was chosen on the basis of literature as a moderate supplementation to avoid potential toxicity of hypervitaminosis (for review, see Penniston and Tanumihardjo, 2006). Diets started as soon as mice arrived in the laboratory (i.e., at the age of 12-13 months) and continued throughout the entire experiment.

\section{RA TREATMENT}

Middle-aged treated group (12-month-old, $n=39$ ) was fed with a control diet containing 5 IU retinol/g (INRA, Jouy-en-Josas) during 2 months and divided into two groups: one group received daily subcutaneous injections of the vehicle (Mid-age + vehicle, $n=20$ ), and the second group received RA treatment (Midage + RA, $n=19)$. RA (150 $\mu$ g of all-trans-RA/kg body weight, 
Sigma, France) was dissolved in a mixture (vehicle) containing polyethylene glycol-NaCl-ethanol (70:20:10, by volume) and injected during 5 days. This dose of RA was shown to be effective in reversing age-related hypoexpression of brain signaling and its associated memory impairment in mice (Etchamendy et al., 2001).

\section{EXPERIMENTAL DESIGN}

\section{Experimental design displayed in Figure 1}

In the first experiment, we tested the effects of 2 months of nutritional vitamin A supplementation administered to 12-month-old mice on memory in the CSD task. Thus, after 2 months of diet, middle-aged mice (Mid-age, $n=12$ ) and enriched middle-aged mice (Mid-age + Vitamin A, $n=10$ ) were tested in the CSD task.

In the second experiment, we tested the effects of RA treatment during 5 days started at middle-age (14-month-old) on memory and hippocampal plasticity. Mice were divided into two groups: mice injected with vehicle are referred to as Mid-age + vehicle ( $n=13$ ) and mice injected with RA are referred to as Mid-age + RA ( $n=13$ ). Mice were injected 4 days (one injection/day) before the acquisition phase of the CSD task and until the test phase which occurred 24-h later. Twenty minutes after the end of the test phase, all groups were sacrificed and hippocampi were quickly dissected in order to study the expression of plasticity-related RA target genes by quantitative RT-qPCR [Synaptophysin, RC3, GAP43 (growth-associated protein 43 or neuromodulin), PSD-95].

In the third experiment, the effects of RA treatment were studied on hippocampal CORT release after CSD box-induced stress in 14-month-old mice. Similarly as in Experiment 2, mice were divided into Mid-age + RA $(n=7)$ and Mid-age + vehicle $(n=6)$. After five consecutive days of injections, at the same time of behavioral testing, microdialysis experiment was performed.

\section{Experiment 1: Effect of 2 months vitamin A supplementation on D1 retrieval}

12-13 month-old mice

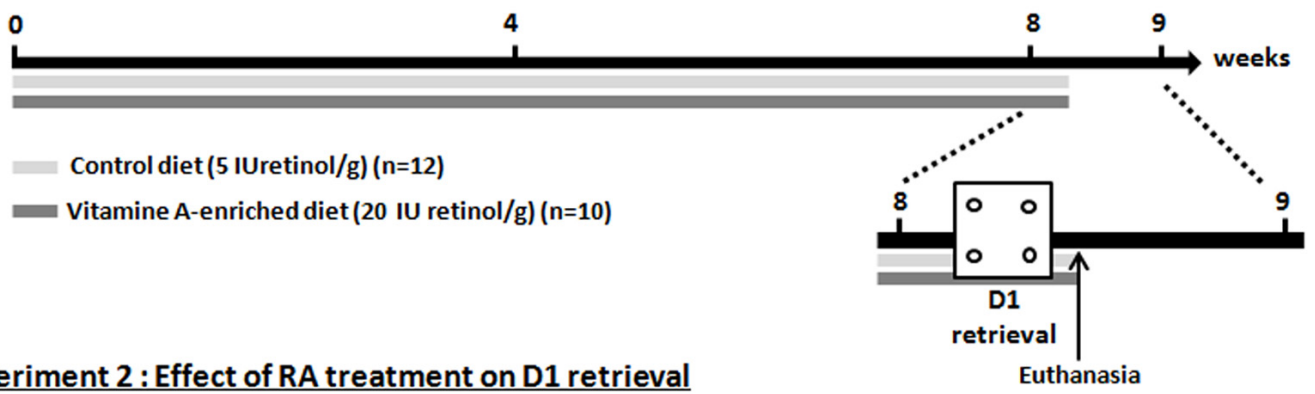

\section{Experiment 2: Effect of RA treatment on D1 retrieval}

Euthanasia

12-13 month-old mice

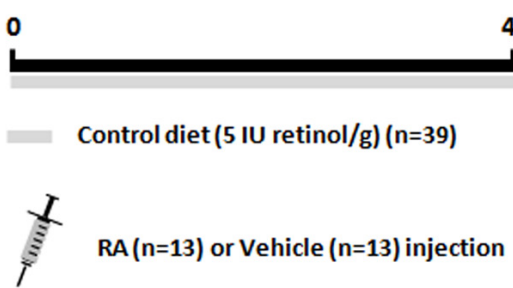

Experiment 3: Effect of RA treatment on hippocampal cortiscosterone levels

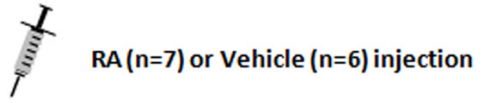

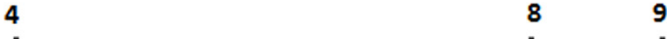

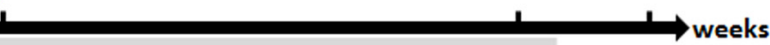

$\Rightarrow$ weeks

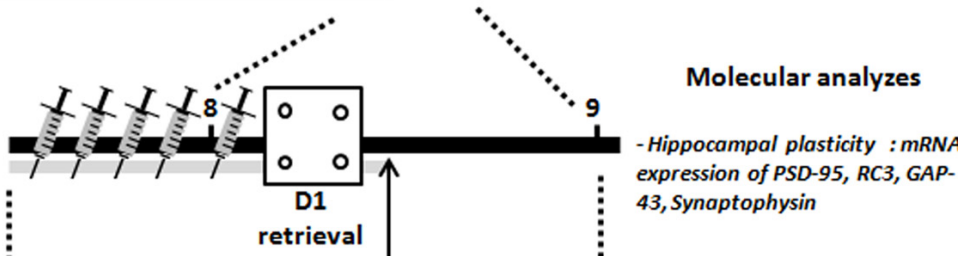

Euthanasia

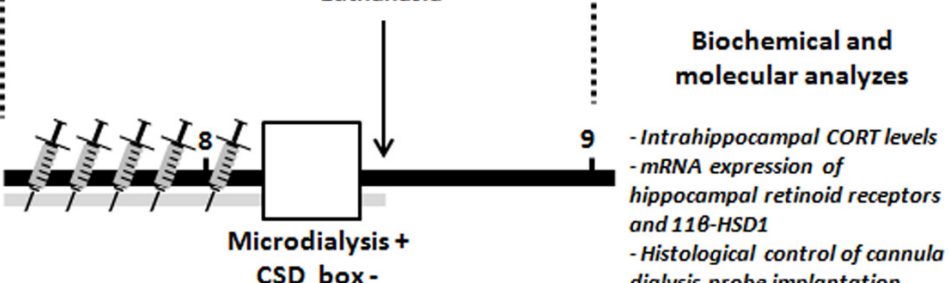

induced stress
FIGURE 1 | Experimental design. Three experiments are carried out. Experiments 1 and 2 are designed to compare the effects of vitamin A supplementation and RA treatment on memory retrieval in the contextual serial discrimination (CSD) task. The Experiment 3 aims to determine the effects of RA treatment on hippocampal CORT relevels in novelty-induced stress. At the end of the Experiments 2 and 3, animals are euthanized, hippocampi and half-brain were dissected in order to carry out RT-PCR measurement (Experiments 2 and 3) and histological control of guide cannula implantation (Experiment 3). The arrows and the bars indicate the time spent and the diet received, respectively. Each needle represented one daily injection of RA or vehicle treatment. 
After a basal period which lasted $60 \mathrm{~min}$ in the microdialysis bowl, animals were placed in the CSD-like box for $10 \mathrm{~min}$ and cerebrospinal fluid (CSF) was collected during 105 min post-stress period. Twenty-four hours later, animals were sacrificed and hippocampi were collected in order to evaluate the expression of retinoid receptors (RARs) and GCs-related RA target genes as $11 \beta$-HSD1.

\section{Contextual serial discrimination task apparatus}

The CSD task has been extensively described in earlier studies (Celerier et al., 2004; Beracochea et al., 2008a,b; Chauveau et al., 2009a,b). All tests were performed in a 4-hole board apparatus $(45 \mathrm{~cm} \times 45 \mathrm{~cm} \times 30 \mathrm{~cm}$ high) enclosed by gray Plexiglas. The 4-hole board apparatus was placed on the floor of the room (3.0 $\mathrm{m} \times 3.0 \mathrm{~m} \times 2.40 \mathrm{~m}$ high). The floor of the board was interchangeable (white and rough; black and smooth). On the floor, four holes opening on a food cup $(3 \mathrm{~cm}$ diameter, $2.5 \mathrm{~cm}$ in depth) were located $6 \mathrm{~cm}$ away from the side-walls. The apparatus was placed in a room exposed to a $60-\mathrm{dB}$ background noise and a light centered over the apparatus provided 20 lux intensity at the position of the apparatus. The apparatus was cleaned with 95\% ethanol, then with water before each mouse behavioral testing. Data were automatically monitored by photoelectric cells and video recording.

\section{Acquisition phase}

In the CSD, the acquisition phase took place in room A where animals learned two consecutive spatial discriminations (D1 and D2; see Figure 2). Both discriminations differed in terms of the color and texture of the floor (internal context of the 4-hole board) and were separated by a 2-min delay interval. During this delay, the mouse was returned to its home cage in room $\mathrm{B}$. At the beginning of acquisition and retrieval phases, mice were placed in the center of the 4-hole board in an opaque PVC tube for $5 \mathrm{~s}$ to provide the animal with a random start in the apparatus. For D1, ten $20-\mathrm{mg}$ food pellets were available only in one of the four holes on the board for $6 \mathrm{~min}$. Location of the baited hole for D1 was randomized for each subject. For D2, ten 20-mg food pellets were consistently located in the opposite symmetrical hole, for 6 min likewise. The environmental spatial cues were made of colored and striped paper sheets positioned at $1.00 \mathrm{~m}$ above the 4-hole board. These allocentric cues remained at the same place for both D1 and D2 discriminations and for the retrieval phase. Thus, both discriminations D1 and D2 differed

A

\section{ACQUISITION PHASE RETRIEVAL}

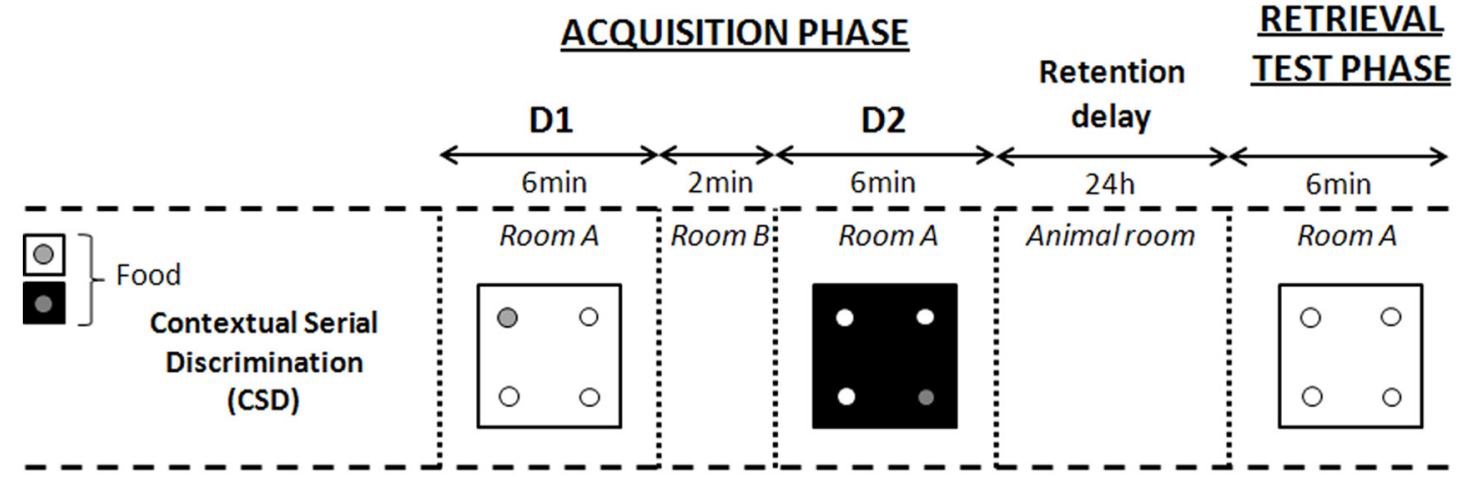

B

Guide cannula microdialysis implantation

\begin{tabular}{|c|c|c|c|}
\hline & 7 days & overnight & $75 \mathrm{~min}$ \\
\hline & Animalroom & Room C & Room C \\
\hline Microdialysis & & Perfusion & $\begin{array}{c}\text { Baseline } \\
\text { period }\end{array}$ \\
\hline
\end{tabular}

TO
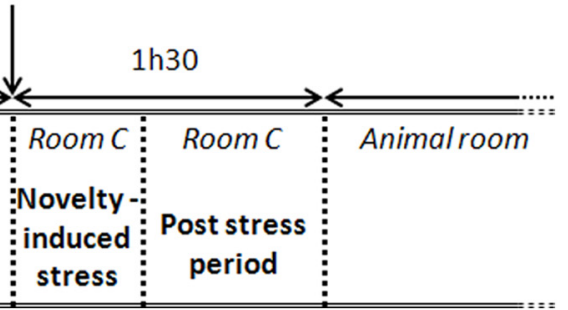

FIGURE 2 | Experimental procedures. (A) Experimental procedure of the contextual serial discrimination (CSD) behavioral task. D1, discrimination 1; D2, discrimination 2. During retrieval test phase, each mouse is evaluated on D1 floor without food reward. (B) Detailed description of microdialysis procedure. Time 0 (TO) corresponds to the last point of

the basal period (pre-stress) just before the beginning of the exploration in the CSD-like box. This novelty-induced stress induces an increased hippocampal CORT levels. Thus, microdialysates collected at time 15 (post-stress) corresponds to the CORT levels released between 0 and 15 min after stress. 
only by way of the internal (floor) contextual cues. Both floors were positioned in a mixed random order during the acquisition of the first and second discrimination tasks. At the end of the acquisition phase, mice returned to their home cage in the animal room for $24 \mathrm{~h}$. Only mice having eaten all the pellets during both acquisition sessions were used for the retrieval test phase.

\section{Test phase}

Twenty-four hours after the acquisition phase, mice were replaced in the 4-hole board (room A) without any pellets in the apparatus. Mice were placed on the D1 floor and were allowed to freely explore the apparatus for $6 \mathrm{~min}$. Performance was assessed by measuring the number of head-dips in each hole during $6 \mathrm{~min}$.

\section{Measurements}

Memory retrieval performance was evaluated through the exploration rates into the different holes. Correct responses were defined as head-dips into the hole previously baited on the same floor-context during the acquisition phase, and were calculated as follows: (head-dips into the baited hole/total number of head-dips in the four holes) $\times 100$. Interfering responses were defined as head-dips into the hole previously baited on the other floor-context in the acquisition phase and were calculated on same manner as correct responses. Chance level was $25 \%$.

\section{SURGERY AND HISTOLOGY}

For Experiment 3, 1 week before the microdialysis study, mice were anesthetized with a ketamine $(100 \mathrm{mg} / \mathrm{kg}$ body weight)xylazine $(10 \mathrm{mg} / \mathrm{kg}$ body weight $)$ solution and placed into a stereotaxic frame. A single guide cannula microdialysis (CMA/7 Microdialysis probe, CMA Microdialysis, Sweden) was implanted randomly in the left or the right hemisphere, in the bottom of the parietal cortex at the following coordinates from the bregma (Paxinos and Franklin, 2001): anteroposterior $=-2000 \mu \mathrm{m}$, lateral $= \pm 1400 \mu \mathrm{m}$, and vertical $=-900 \mu \mathrm{m}$. The guide cannula was fixed with dental cement to the skull. All operated mice were allowed to recover in their home cages in the animal room for at least 7 days before the microdialysis experiment. On the day of experiment, the microdialysis probe was lowered $1 \mathrm{~mm}$ below through the guide cannula so that the microdialysis membrane is located into the dorsal hippocampus. At the end of the microdialysis experiment, mice were euthanatized and the half of the brain containing the guide cannula was dissected, washed into a saline solution $(\mathrm{NaCl} 0.9 \%)$ and postfixed in a $4 \%$ paraformaldehyde solution. After 3 weeks postfixation period, $50 \mu \mathrm{m}$ frontal sections were cut on a vibratome (Leica). A cresyl violet stain was used to locate the microdialysis probe with utmost accuracy.

\section{IN VIVO MICRODIALYSIS}

Seven days after surgery, a dialysis probe (CMA/7; CMA Microdialysis $A B$, Sweden; length: $1 \mathrm{~mm}$; molecular cut-off $6 \mathrm{kDa}$ and membrane diameter: $0.24 \mathrm{~mm}$ outer diameter) was carefully implanted into the right or left dorsal hippocampus. Mice were then individually housed in a system allowing animals to move freely (CMA/120; CMA Microdialysis AB, Sweden) overnight. After the overnight perfusion at $0.5 \mu \mathrm{L} / \mathrm{min}$, freely moving animals were continuously perfused with a sterile-filtered saline solution (Dulbecco's phosphate buffered saline; SIGMA; in $\mathrm{g} / \mathrm{L}: \mathrm{CaCl}_{2}, 0.133 ; \mathrm{MgCl}_{2}, 0.1 ; \mathrm{KCl}, 0.2 ; \mathrm{KH}_{2} \mathrm{PO}_{4}, 0.2$; $\mathrm{NaCl} 8.0 ; \mathrm{Na}_{2} \mathrm{HPO}_{4}, 1.15 ; \mathrm{pH}$ between 7.1 and 7.5) at a 1$\mu \mathrm{L} / \mathrm{min}$ flow rate through a micro-infusion pump. Baseline dialysates were collected for 60 min before novelty-induced stress task. During the novelty-induced stress, animals were carefully placed in an open field square box similar to the CSD box $(45 \mathrm{~cm} \times 45 \mathrm{~cm} \times 30 \mathrm{~cm}$ high). After $10 \mathrm{~min}$ exploration, animals were then relocated in the microdialysis freely moving chamber for $95 \mathrm{~min}$. Microdialysates were sampled every $15 \mathrm{~min}$ using tubes with a dead volume of $1.2 \mu \mathrm{L} / 100 \mathrm{~mm}$ length (CMA Microdialysis AB). Samples were stored at $80^{\circ} \mathrm{C}$. Free CORT levels measured in the dialysates (in $\mathrm{nM}$ ) were expressed as the percentage of the averaged baseline values collected before the injection.

\section{INTRA-HIPPOCAMPAL CORT ASSAY}

A commercially prepared Enzyme Immunoassay kit was used to measure HPC CORT concentrations in the microdialysates (Correlate-EIA $^{T M}$, Assay Designs, Ann Arbor, USA) according to the manufacturer's instructions. The sensitivity of the assay was $0.08 \mathrm{nmol} / \mathrm{L}$. Therefore, baseline sample concentration was more than 10 -fold superior than sensitivity threshold.

\section{REAL-TIME qPCR ANALYSIS OF TARGET GENE EXPRESSION IN THE HIPPOCAMPUS}

The other half of the hippocampus was used to measure gene expression. Extraction of RNA was conducted using an extraction kit (TRIzol reagent, Invitrogen, Saint Aubin, France) according to the manufacturer's instructions. The integrity of the purified RNA was verified using the RNA 6000 Nano LabChip kit in combination with the 2100 bioanalyzer (Agilent Technologies). The concentrations of RNA were determined by using a nanodrop (ND-1000; Labtech). Using OligodT and random primers (Promega, Charbonnières-les-Bains, France), cDNA was synthesized from $1 \mu \mathrm{g}$ of RNA with ImPromII reverse transcriptase (Promega, Charbonnières-les-Bains, France) according to the manufacturer protocol. The real-time qPCR was performed using the LightCycler 480 system with a 96-well format (Roche Diagnostics) in a volume, containing $1 \times$ LightCycler 480 SYBR Green I Master solution, $0.5 \mu \mathrm{M}$ of each primer and $6 \mu \mathrm{L}$ of cDNA. The forward and reverse primer sequences are summarized in Table 1. The results are expressed as the target/reference ratio divided by the target/reference ratio of the calibrator.

\section{STATISTICAL ANALYSIS}

Contextual serial discrimination test and RT-qPCR data were analyzed by a one-way analysis of variance (ANOVA): effect of vitamin A or RA treatment. Comparisons of retrieval performance with chance level were calculated with a one sample $t$-test (with hypothesized mean $=$ chance level $=25 \%$ ). Hippocampal CORT release was analyzed using a two-way ANOVA with repeated measures: effect of RA treatment and Time. All results were expressed as mean \pm SEM. 
Table 1 | Primers used for LightCycler RT-qPCR.

\begin{tabular}{|c|c|c|}
\hline Gene name & Nucleotide sequence $5^{\prime}-3^{\prime}$ & $\begin{array}{l}\text { Product } \\
\text { length (bp) }\end{array}$ \\
\hline \multirow[t]{2}{*}{ GAPDH } & F: CCAGTGAGCTTCCCGTTCA & 78 \\
\hline & R: GAACATCATCCCTGCATCCA & \\
\hline \multirow[t]{2}{*}{ Actin } & F: AAAACGCAGCTCAGTAACAGTCC & 220 \\
\hline & R: AGGATGCAGAAGGAGATTACTGC & \\
\hline \multirow[t]{2}{*}{ Synaptophysin } & F:TCCTTGCATGTGTTTCCTGTCTG & 137 \\
\hline & R: GCAGTGTTCGCTTTCATGTGG & \\
\hline \multirow[t]{2}{*}{ PSD-95 } & F:TGGATCACAGGGTCGAGAAG & 101 \\
\hline & R: CTTTGGTAGGCCCAAGGATG & \\
\hline \multirow[t]{2}{*}{$\mathrm{RC} 3$} & F: CACTCTCCGCTCTTTAATCTTCTTC & 127 \\
\hline & R: GCTCCAAGCCAGACGACGATATTC & \\
\hline \multirow[t]{2}{*}{ GAP-43 } & F: GGGGAGTTATCAGTGGTAGC & 255 \\
\hline & R: GTGATGCACCAGCTGCTGAGG & \\
\hline \multirow[t]{2}{*}{$\operatorname{RAR} \alpha$} & F: GGCGAACTCCACAGTCTTAATG & 118 \\
\hline & R: GCTGGGCAAGTACACTACGAAC & \\
\hline \multirow[t]{2}{*}{$\operatorname{RAR} \beta$} & F: GGGGTATACCTGGTACAAATTCTGA & 227 \\
\hline & R: CAGCTGGGTAAATACACCACGAA & \\
\hline \multirow[t]{2}{*}{ RAR $\gamma$} & F: CCCAAGGATGCTGATGAAAATC & 63 \\
\hline & R: GCCCTTTCTGCTCCCTTAGTG & \\
\hline \multirow[t]{2}{*}{$11 \beta-H S D 1$} & F: GGAAGGTCTCCAGAAGGTAGTGTC & 51 \\
\hline & R: GAGGCTGCTCCGAGTTCAAG & \\
\hline
\end{tabular}

Sequences are shown for forward (F) and reverse (R) primers. GAPDH, glyceraldehyde-3-phosphate dehydrogenase-like; PSD-95, postsynaptic density protein 95; RC3, neurogranin; GAP-43, growth associated protein 43; RARs, retinoic acid receptors; 11ß-HSD1, 11-beta-hydroxysteroid dehydrogenase type 1.

\section{RESULTS}

\section{EFFECTS OF VITAMIN A SUPPLEMENTATION AND SHORT-TERM RA} TREATMENT ON CONTEXTUAL SERIAL DISCRIMINATION MEMORY

In the present experiment, we compared the effects of 2 months of vitamin A supplementation and short-term RA treatment on D1 retrieval in middle-aged mice (Figure 3 ).

\section{Acquisition phase}

The acquisition phase of groups tested for D1 was analyzed according to the further random attribution of mice to different diet or treatment conditions (Control vs Vitamin A, Vehicle vs RA) No between-group difference was observed on behavioral measures (number of head-dips into baited holes, total number of head-dips; n.s. in all comparisons - data not shown).

\section{Retrieval test phase - correct responses}

As shown in Figure 3A, one-way ANOVA of percentage of correct responses in D1 retrieval test revealed no effect of vitamin A supplementation $[F(1,20)=3.23, p=0.087$; Mid-age + Vita$\min$ A: $38.59 \pm 3.81 \%$ vs Mid-age: $30.26 \pm 2.80 \%$ ]. However, the enriched middle-aged group exhibited performances significantly above the chance level (different from 25\%; one sample test $p<0.01)$ compared to control middle-aged mice which performed at chance (one sample test $p=0.087$, n.s.). As shown in Figure 3B, a significant improvement of memory retrieval was observed in middle-aged mice receiving RA treatment compared to the vehicle-treated group $[F(1,24)=25.32, p<0.001$; Midage + RA $50.66 \pm 3.16 \%$ vs Mid-age + vehicle: $25.68 \pm 3.82 \%]$. In addition, D1 performance of RA-treated mice was significantly above the chance level (one sample test $p<0.0001$ ) showing that they accurately remember the previously baited hole, in contrast to vehicle-treated mice.

\section{Retrieval test phase - interfering responses}

During retrieval of D1, interfering responses consisted of exploration into the hole baited on discrimination D2. As shown in Figure 3C, one-way ANOVA analyzes revealed that vitamin A supplementation does not affect the percentage of responses in the interfering hole $[F(1,20)=3.18, p=0.90$; Mid-age + Vitamin A: $27.48 \pm 4.29 \%$ vs Mid-age $36.98 \pm 3.31 \%$ ]. However, as seen in Figure 3D, one-way ANOVA showed that RA-treated mice exhibited significantly less interfering responses than vehicle control mice $[F(1,24)=15.18, p<0.001$; Mid-age + RA: $21.88 \pm 2.20 \%$ vs Mid-age + vehicle: $39.42 \pm 3.93 \%$ ]. In addition, the percentage of responses in the interfering hole was above the chance level for the vehicle-treated mice (one sample test $p=0.003$ ) confirming impaired contextual retrieval for D1, whereas RA-treated mice performed at chance (one sample test $p=0.182$, n.s.).

In conclusion, our results demonstrate that both vitamin A supplementation and RA treatment improve memory performances in the CSD task. However, a short-term RA treatment in middleaged subjects was more efficient to improve retrieval of D1 context than 2 months of vitamin A supplementation. Thus, short-term RA treatment was chosen in our subsequent experiments to study the effects of retinoid pathways stimulation in middle-aged mice on hippocampal CORT levels and hippocampal expression of retinoid-target genes.

\section{EFFECTS OF RA TREATMENT ON HIPPOCAMPAL EXPRESSION OF PLASTICITY-RELATED GENES}

In order to study the possible neurobiological mechanisms underlying the improvement of memory performances in RA-treated mice, we tested whether RA treatment can modulate expression of some hippocampal plasticity genes such as synaptophysin, PSD95, RC3 (neurogranin), and GAP-43, measured 20 min after the end of the CSD task. As shown in Figure 4, one-way ANOVA performed on mRNA expression of hippocampal PSD-95 revealed an effect of RA treatment $[F(1,9)=10.46, p=0.01]$. Indeed, an increase of PSD-95 expression $(+13 \%)$ was found in RA-treated mice. However, no effect of RA treatment was found on the mRNA expression of synaptophysin, RC3, and GAP-43 $[F(1,9)=0.008$, n.s., $F(1,9)=1.90$, n.s., and $F(1,9)=0.009$, n.s., respectively].

\section{EFFECTS OF RA TREATMENT ON HIPPOCAMPAL CORT RELEASE}

We studied the involvement of hippocampal CORT in the effects of RA treatment on hippocampal plasticity and functions in middleaged mice. Thus, CORT levels in hippocampal dialyzates were analyzed in basal conditions and after CSD box-induced stress according to the further random attribution of mice to vehicle or RA-treated groups. 


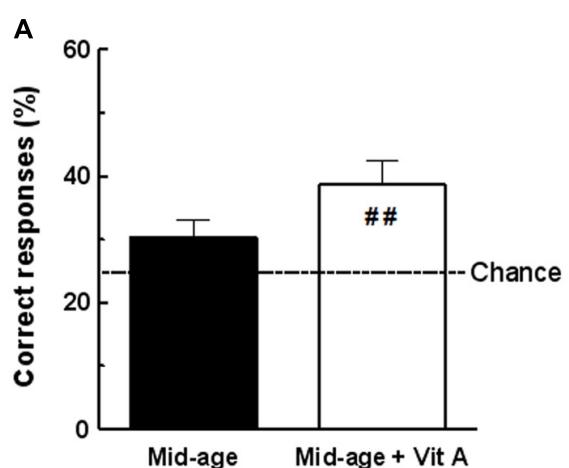

C

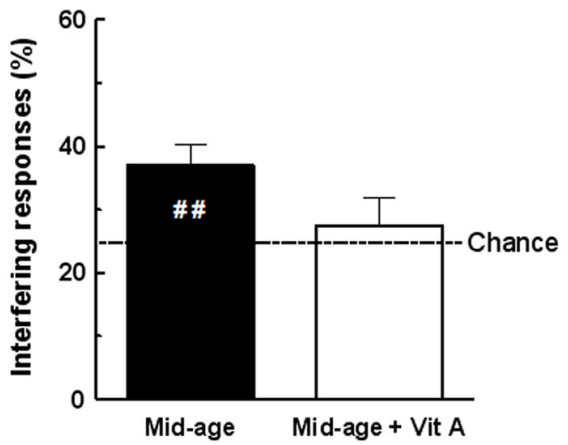

FIGURE 3 | Effects of vitamin A supplementation and RA treatment on D1 retrieval. (A) The percentage of correct responses for vitamin A

supplemented group was different from the chance level (25\%) compared to control group. (B) The percentage of correct responses for RA-treated group was increased compared to vehicle and different from chance level. (C) The percentage of interfering responses for vitamin A supplemented

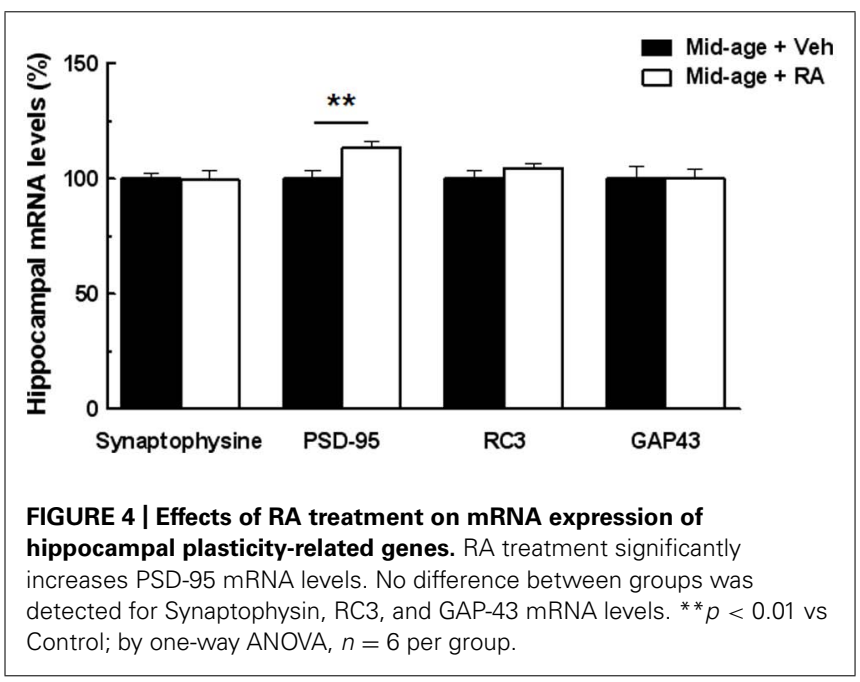

As shown in Figure 5A, a photomicrograph of coronal brain section stained with cresyl violet from a typical mouse shows that microdialysis probe were located inside the dorsal hippocampus, between CA1 and DG areas. Figure 5B represents CORT levels in the dorsal hippocampus and results are expressed in percentage of variation of baseline.

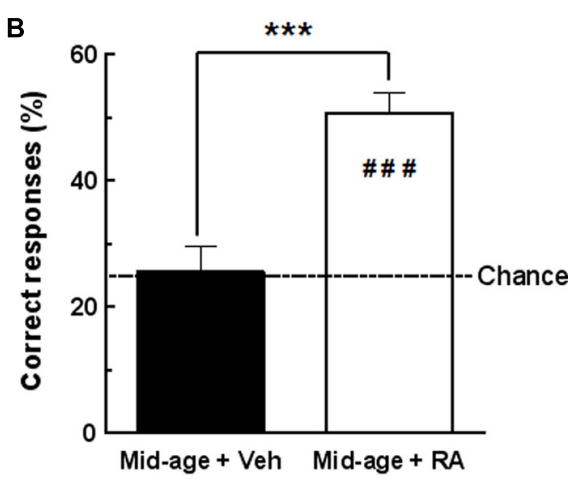

D

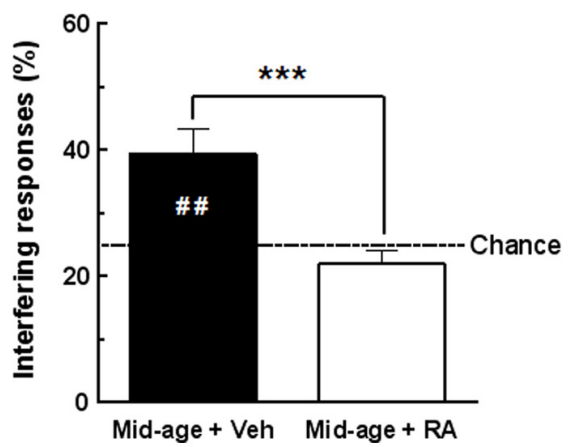

group was not significantly different from chance level compared to control group. (D) Percentage of interfering responses for RA-treated group was significantly decreased compared to vehicle and was not different from chance level. ${ }^{* * *} p<0.001$ vs Control by one-way ANOVA; ${ }^{\# \#} p<0.01$ vs Chance, ${ }^{\# \# \#} p<0.001$ vs Chance, by one sample $t$-test. $n=10-13$ per group.

\section{Basal hippocampal corticosterone levels}

Two-way ANOVA on hippocampal CORT levels (Figure 5B) along the basal period ( -60 to $0 \mathrm{~min}$ ) evidenced no global effect of treatment $[F(1,11)=1.77$, n.s. $]$, nor interaction treatment $\times$ time $[F(4,44)=1.00$, n.s. $]$ showing no differences in basal hippocampal CORT between groups (Mid-age + vehicle: $1.11 \pm 0.20 \mathrm{nM}$ vs Mid-age + RA: $1.61 \pm 0.37 \mathrm{nM}$.)

\section{Hippocampal corticosterone levels after CSD box-induced stress}

Two-way ANOVA performed on hippocampal CORT released along the post-stress period (from 0 to $105 \mathrm{~min}$ ) revealed a global effect of RA treatment $[F(1,11)=4.54, p=0.05]$, an effect of time $[F(7,77)=4.43, p<0.0001]$ with an interaction treatment $\times$ time $[F(7,77)=2.47, p<0.05]$. Firstly, as compared to the last pre-stress sample $(121.08 \pm 7.66 \%$; time 0$)$, stress induced a fast and rapid increase in CORT levels from $15 \mathrm{~min}$ after stress $(165.36 \pm 16.58 \%)$ to $105 \mathrm{~min}(220.55 \pm 32.15 \%)$ in vehicle-treated mice. Moreover, a faster increase in CORT levels was observed $15 \mathrm{~min}$ after CSD box-induced stress in control middle-aged mice as compared to RA-treated middleaged mice $[F(1,11)=3.91, p=0.07$; Mid-age + vehicle: $165.36 \pm 16.58 \%$ vs Mid-age + RA: $114.93 \pm 18.80 \%]$ as well as $30 \min [F(1,11)=4.04, p=0.07$; Mid-age + vehicle: $192.71 \pm 38.7 \%$ vs Mid-age + RA: $116.50 \pm 11.97 \%$ ], $45 \mathrm{~min}$ 
A

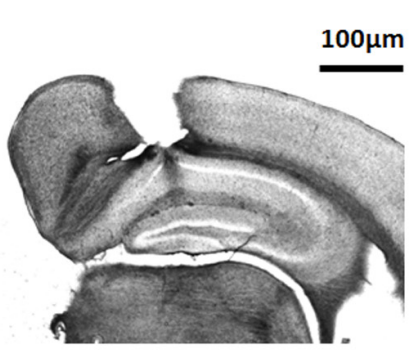

B

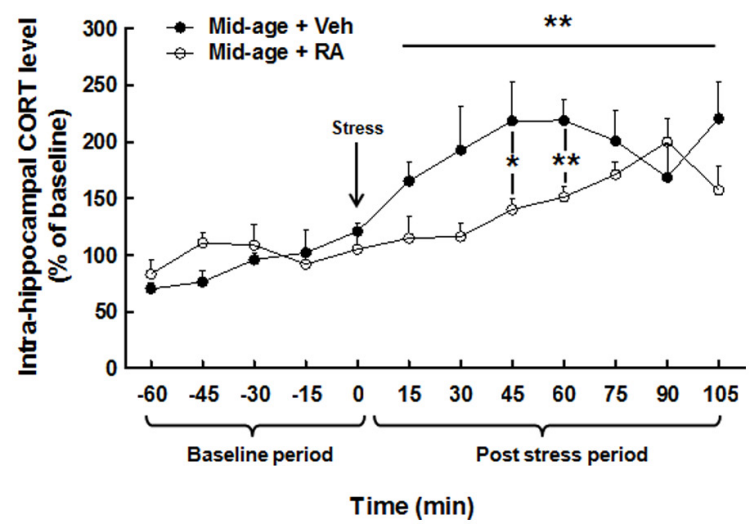

FIGURE 5 | Effects of RA treatment on hippocampal CORT release. (A) Histological control of intra-hippocampal microdialysis probe implantation. Photomicrograph $(\times 20)$ of coronal brain section stained with cresyl violet. Stereotaxic coordinates from bregma: $A P=-2000 \mu \mathrm{m}, \mathrm{L}= \pm 1400 \mu \mathrm{m}$, and $\mathrm{V}=-900 \mu \mathrm{m}$. (B)
Hippocampal CORT concentration was similar for all groups during basal period. During post-stress period, RA-treated group showed a decrease in hippocampal CORT levels particularly at 45 and 60 min after stress. ${ }^{*} p<0.05,{ }^{*} p<0.01$, by two-way ANOVA with repeated measures and one-way ANOVA, $n=6-7$ per group.
$[F(1,11)=5.56, p<0.05 ;-78 \%$ between Mid-age + vehicle: $218.48 \pm 34.42 \%$ and Mid-age + RA: $140.26 \pm 9.22 \%]$ and $60 \mathrm{~min}$ $[F(1,11)=11.43, p<0.01 ;-77 \%$ between Mid-age + vehicle: $218.8 \pm 18.88 \%$ and Mid-age + RA: $151.36 \% \pm 9.05 \%]$ after stress delivery.

Thus, CSD box-induced stress significantly increased hippocampal CORT levels in middle-aged rats but the stress-induced CORT rise was lower and delayed for an extended period of time in RA-treated middle-aged mice.

\section{EFFECTS OF RA TREATMENT ON HIPPOCAMPAL EXPRESSION OF RETINOID RECEPTORS AND 11 $\beta$-HSD1}

In order to study the relationships between retinoid and GC pathway, hippocampal expression of RARs and $11 \beta$-HSD1 was assessed in middle-aged mice. For gene expression, results are expressed in percentage of variation by comparison to vehicle-treated group.

As seen in Figure 6A, one-way ANOVA performed on hippocampal RAR $\alpha$ mRNA expression showed an effect of RA treatment $[F(1,10)=19.16, p<0.01]$. Indeed, RA treatment induced a decreased RAR $\alpha$ expression (-14\%) compared to vehicle-treated mice. By contrast, hippocampal RAR $\beta$ mRNA expression is increased by $38 \%$ compared to vehicle-treated mice [ANOVA, effect of RA treatment, $F(1,10)=53.88, p<0.001$ ]. Finally, no effect of RA treatment was detected on hippocampal RAR $\gamma$ expression $[F(1,10)=0.55$, n.s. $]$. As shown in Figure 6B, hippocampal mRNA expression of $11 \beta$-HSD1 was not affected by RA treatment $[F(1,10)=0.32$, n.s. $]$.

Moreover, correlations analyzes were performed between hippocampal expression of RARs and intrahippocampal CORT levels in order to study interactions between RA and GCs signaling pathways (Figure 7). Correlation analyzes between hippocampal expression of $\operatorname{RAR} \alpha$ and CORT levels showed that a decreased expression of $\operatorname{RAR} \alpha$ was associated to a lower hippocampal CORT release 45 and $60 \mathrm{~min}$ post-stress (Figures 7A,B, $r=0.55, p<0.05$ and $r=0.59, p<0.05$, respectively).

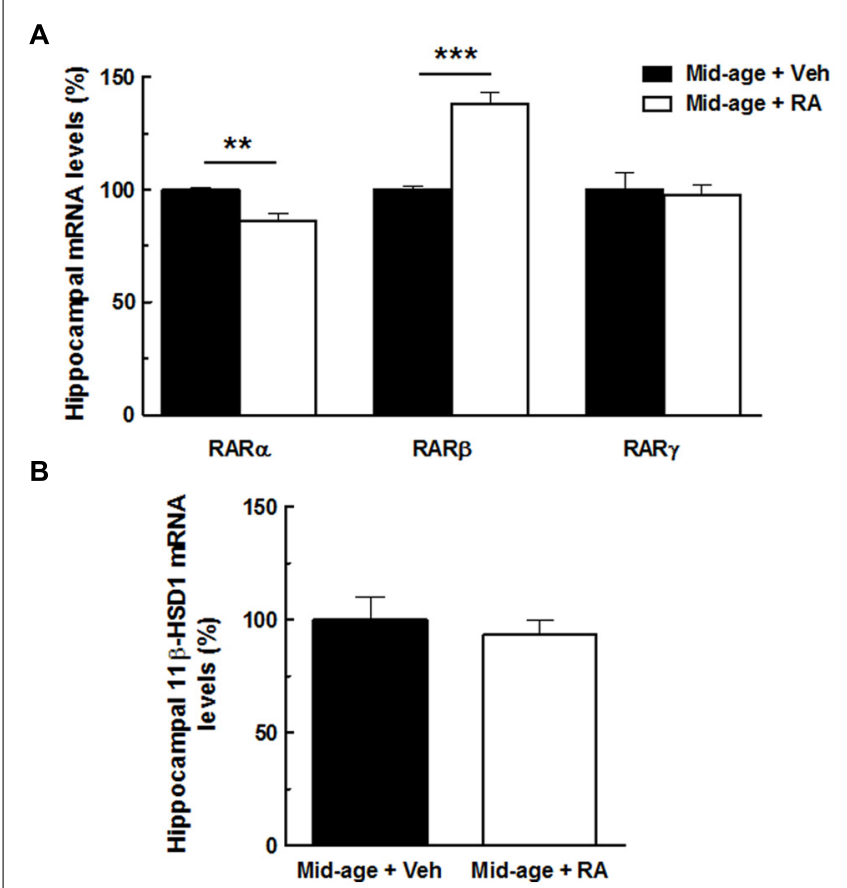

FIGURE 6 | Effects of RA treatment on hippocampal expression of RARs (RAR $\boldsymbol{\alpha}, \mathbf{R A R} \boldsymbol{\beta}, \mathbf{R A R} \boldsymbol{\gamma}$ ) and $\mathbf{1 1} \boldsymbol{\beta}$-HSD1. (A) The percentage of RAR $\alpha$ mRNA expression was decreased by RA treatment whereas the percentage of RAR $\beta$ mRNA expression was increased by the treatment. No effect on RAR $\gamma$ expression was found. (B) RA treatment did not modulate hippocampal mRNA levels of $11 \beta-H S D 1$. By one-way ANOVA, $n=6-7$ per group. ${ }^{* *} p<0.001$ vs Mid-age + Veh; ${ }^{* *} p<0.01$ vs Mid-age + Veh, by one-way ANOVA, $n=6-7$ per group.

Moreover, correlation analyzes revealed a strong negative correlation between intrahippocampal CORT levels and hippocampal expression of RAR $\beta 45$ and 60 min post-stress (Figures 7C,D, 
A

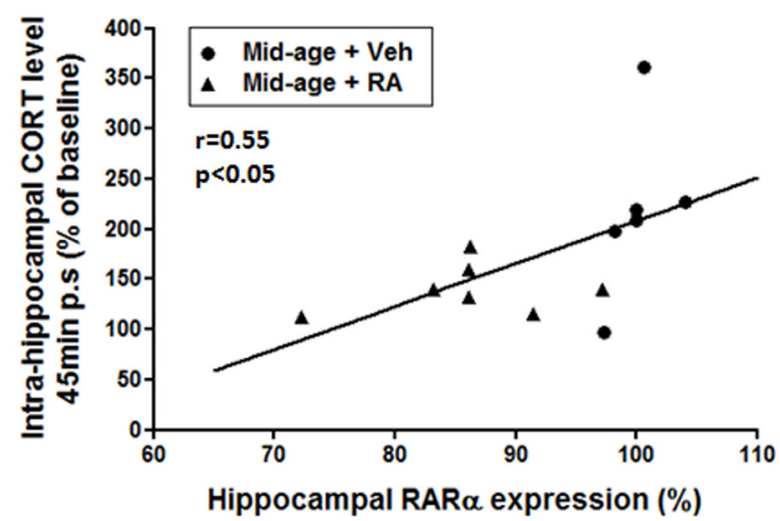

C

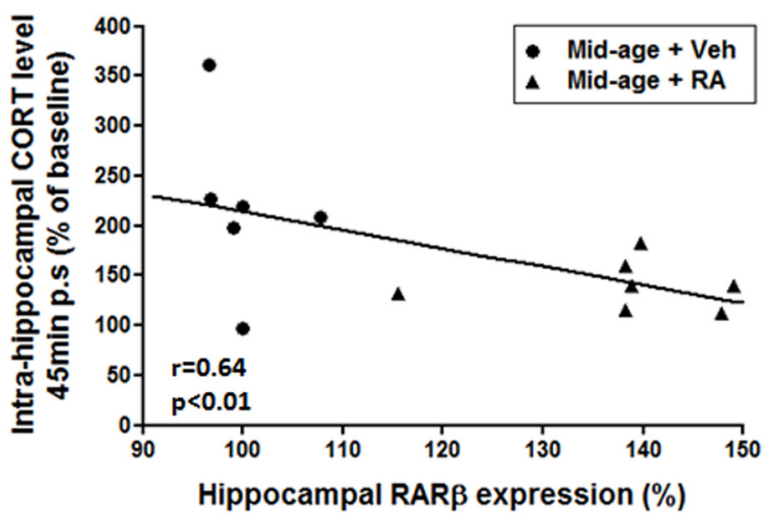

FIGURE 7 | Relationships between hippocampal expression of RARs (RAR $\alpha, R A R \beta$ ) and intrahippocampal CORT levels. (A,B) Correlation analyzes between RAR $\alpha$ and CORT levels. Intrahippocampal CORT levels [45 $\mathrm{min}$ (A) and $60 \mathrm{~min}$ (B) post-stress] positively correlated with RAR $\alpha$ hippocampal mRNA expression $(r=0.55, p<0.05$ and
B

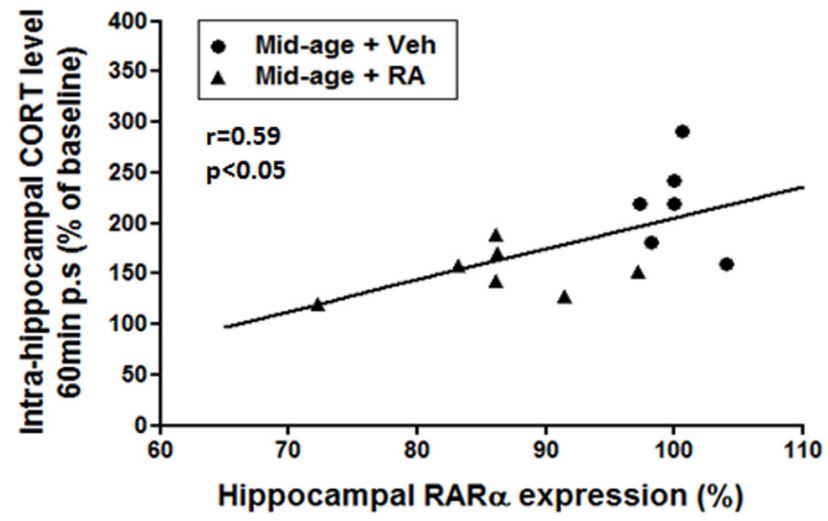

D

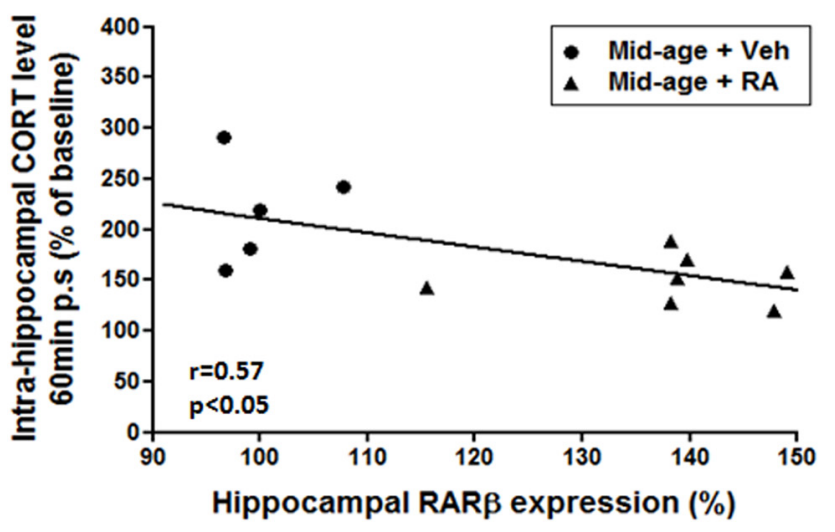

$r=0.59, p<0.05$, respectively). (C,D) Correlation analyzes between RAR $\beta$ and CORT levels. Intrahippocampal CORT levels [45 min (C) and $60 \mathrm{~min}$ (D) post-stress] negatively correlated with RAR $\beta$ hippocampal mRNA expression $(r=0.64, p<0.01$ and $r=0.57, p<0.05$, respectively). $r=0.64, p=0.01$ and $r=0.57, p<0.05$, respectively): low intrahippocampal CORT was associated with elevated expression of RAR $\beta$. Finally, no significant correlation was found between hippocampal CORT levels and hippocampal RAR $\gamma$ expression.

Thus, these data sustained the idea that the modulation of RA signaling pathway by RA treatment during mid-life can modulate GCs activity in the hippocampus.

\section{DISCUSSION}

The aim of this study was to explore the involvement of retinoids in the modulation of intrahippocampal CORT levels in middleaged mice and its impact on hippocampal plasticity and functions. Middle-aged mice treated with five daily consecutive injections of RA retrieve better D1 discrimination in CSD task than mice fed with 2 months of vitamin A supplementation showing that RA treatment seems to be more efficient than vitamin A supplementation. Moreover, we show that the improvement of D1 retrieval by RA treatment is associated with an increased hippocampal PSD-95
mRNA expression, one of plasticity-related RA target genes. Interestingly, RA treatment can decrease and delay the stress-induced increase in dorsal hippocampus CORT rise in middle-aged mice. This effect cannot be related to a modulation of hippocampal 11 $\beta$-HSD1 expression. In addition, RA treatment induces a modulation of RA receptors $\mathrm{RAR} \alpha$ and $\mathrm{RAR} \beta$ expression in middle-aged mice, which has been correlated with intrahippocampal CORT levels after CSD-box-induced stress, showing that retinoid signaling could be an important modulator of intrahippocampal GCs activity and thereby hippocampal plasticity and functions.

\section{EFFECTS OF RETINOIC ACID TREATMENT ON CSD TASK AND HIPPOCAMPAL EXPRESSION OF PLASTICITY-RELATED TARGET GENES AT MIDDLE-AGE}

We first explored the effects of vitamin A supplementation and RA treatment on CSD task that allows the detection of early signs of age-related hippocampal-dependent memory deficits (Chauveau et al., 2010; Tronche et al., 2010). Studies in middle-aged mice have important implications for the treatment of the non-pathological 
age-associated cognitive decline, as well as mild cognitive impairment (Pepeu, 2004). The effects of stimulation of retinoid pathway on memory performance have not yet been tested in middle-aged rodents. Thus, our study demonstrates for the first time that a mid-life RA treatment is efficient to correct "early" age-related hippocampal-dependent memory deficits. The ability of cells to convert vitamin A into RA, the active metabolite, and therefore to initiate retinoid signaling would be altered during aging (Azais-Braesco et al., 1995). Thus, injections of RA at middle-age, would be more efficient than 2 months of nutritional vitamin A supplementation involving metabolization steps. Our present results show that 2 months of vitamin A supplementation with a dose of $20 \mathrm{IU}$ retinol/g is not sufficient to observe preventive effects on memory processes. However, a recent study of our team has shown that the stimulation of retinoid pathway by 4 months of vitamin A supplementation allowed the correction of hippocampal-dependent memory deficits in aged rodents but in this study, the animals were fed with higher content of vitamin A (45 IU retinol/g) and for a longer time which would be an efficient way of improving metabolism (Etchamendy et al., 2001; Drapeau et al., 2003, 2007; Mingaud et al., 2008; Touyarot et al., 2013).

In our current study, the memory retrieval improvement of D1 observed in middle-aged mice after RA treatment can be ascribed to an improvement of hippocampal-dependent memory function. Indeed, mice with lesion of the dorsal hippocampus exhibited an impaired memory retrieval pattern in the CSD task similar to that of middle-aged mice of the present study (Chauveau et al., 2009b). Deficits in hippocampal-dependent tasks reported in middle-aged rats (Frick et al., 1995; Markowska and Breckler, 1999; Kadish et al., 2009), could result from dysfunction of hippocampal plasticity (Kaczorowski and Disterhoft, 2009). Thus, the modulation of hippocampal plasticity, one plausible mechanism underlying hippocampal memory function would be critical for retention of D1 discrimination in the CSD task. The genes we chose to study are hippocampal plasticity-related RA target genes and all major components of presynaptic and postsynaptic density. Thus, we show that RA treatment is efficient not only to improve hippocampal-dependent memory processes but also hippocampal synaptic plasticity as evaluated by the expression of some plasticity-related RA target genes in middle-aged mice. Interestingly, we demonstrate that RA treatment at mid-life increased hippocampal PSD-95 mRNA expression, known to be involved in memory processes (Migaud et al., 1998; Carlisle et al., 2008). PSD-95 recruits and clusters $N$-methyl-D-aspartate (NMDA) and $\alpha$-amino-3-hydroxy-5-methyl-4-isoxazolepropionic acid (AMPA) receptors, ion channels, cytoskeletal components, and signal transduction molecules in response to synaptic activity (Beique et al., 2006; Vickers et al., 2006). During spatial learning and memory formation, PSD-95 is recruited to synaptic lipid rafts, suggesting that regulated localization as well as expression of this protein is a necessary component of synaptic plasticity (Delint-Ramirez et al., 2008). Alterations in the content of PSD-95 in the hippocampal formation have been observed in aged-learning impaired rats (Nyffeler et al., 2007). In addition, a positive correlation between the decreased expression levels of hippocampal PSD95 and the decline of performance in a hippocampal-dependent spatial memory task have been shown (VanGuilder et al., 2011). Thus, we proposed that the promotion of hippocampal PSD-95 expression in middle-aged mice treated with RA could be one of the plausible mechanisms by which RA treatment might exert promnesic effects in the CSD task. In addition, we show that RA treatment on middle-aged mice does not modify Synaptophysin, RC3, and GAP-43 hippocampal mRNA expression. It has been demonstrated to date that RA treatment or vitamin A supplementation can increase levels expression of RC3 (Etchamendy et al., 2001) and GAP-43 (Mingaud et al., 2008) during aging. However, no effect of vitamin A supplementation nor RA treatment has been evidenced on hippocampal GAP-43 mRNA expression in middle-aged mice (Mingaud et al., 2008) suggesting thereby that the modulation of retinoid status at mid-life would not be efficient to induce changes in these plasticity-related genes and would be more specific to PSD-95.

\section{EFFECTS OF RETINOIC ACID TREATMENT ON INTRAHIPPOCAMPAL CORTICOSTERONE LEVELS: INVOLVEMENT OF RETINOIC ACID RECEPTORS}

In order to better understand some potential mechanisms involved in the regulation of hippocampal plasticity and memory processes in the CSD task by RA treatment, we have tested whether RA signaling pathway could be a regulator of intrahippocampal CORT levels in middle-aged mice. Our study shows that RA treatment does not influence basal levels of intrahippocampal CORT but reduces and delays the CORT rise after CSD-induced stress in middle-aged mice.

Therefore, in order to establish a link between vitamin A status in middle-aged mice and hippocampal CORT rise after stress conditions, we measured the expression of hippocampal retinoid receptors. We show that the low CORT release in middle-aged RA-treated mice has been associated with a decrease in hippocampal RAR $\alpha$ and an increase in RAR $\beta$ mRNA expression levels thus showing that retinoid signaling could be an important modulator of intrahippocampal GCs activity. It has been shown that the hippocampal expression of retinoic receptors is a good indicator of vitamin A status and intracellular availability of RA. Indeed, several studies have demonstrated age-related decreases in mRNA expression or protein levels of retinoid receptors in mice and rat brain (Enderlin et al., 1997; Etchamendy et al., 2001; Feart et al., 2005; Mingaud et al., 2008; Dyall et al., 2010) indicating a decreased bioavailability of the ligand. More specifically, ageinduced decreased RAR $\beta$ in the whole brain has been associated with memory deficits and all these effects can be normalized by RA treatment (Etchamendy et al., 2001). According to these results, we evidence that RA treatment increases hippocampal expression of $\operatorname{RAR} \beta$ in middle-aged while $\operatorname{RAR} \alpha$ is decreased. More importantly, we have shown correlations between hippocampal expression of these retinoid receptors and hippocampal CORT levels. Thus, our results suggested that RA treatment-induced up-regulation of hippocampal RAR $\beta$ but also down-regulation of hippocampal RAR $\alpha$ could contribute to limit hippocampal CORT rise. These results further substantiated our hypothesis of a close relationship between hippocampal retinoid and GC pathways. 


\section{POSSIBLE MECHANISMS INVOLVED IN THE EFFECTS OF RA TREATMENT ON INTRAHIPPOCAMPAL CORT LEVELS 11及-HSD1 hypothesis}

The magnitude of intracellular GCs action is thought to be determined by the activity of $11 \beta$-HSD1 (Seckl, 1997), that is increased during aging in hippocampus and correlated with impaired cognitive performance in the water maze (Holmes et al., 2010). Indeed, $11 \beta$-HSD1 regenerates active GCs from their inactive forms, in specific areas in the adult brain, such as the hippocampus, thereby effectively amplifying intracellular GC levels before they bind to MRs and/or GRs (Holmes et al., 2003). Interestingly, inhibitory effects of RA and vitamin A supplementation have been shown on the expression and the activity of $11 \beta$-HSD1, in differentiated C2C12 myotubes (Aubry and Odermatt, 2009), in obese rats liver (Sakamuri et al., 2011) and in vitamin A deficient rats hippocampus (Arvy etal., 2013). Thus, we suggest that the effect of RA treatment on hippocampal CORT levels could directly be mediated, through retinoid receptors which act as transcription factors. However, our results show that hippocampal $11 \beta$-HSD1 expression is not modulated by RA treatment in middle-aged mice suggesting that other mechanisms would lead to a modulation of hippocampal CORT levels.

\section{Modulation of HPA axis}

Another hypothesis would be a dysfunctioning of the HPA axis in response to stress in middle-aged mice and a subsequent deregulation of hippocampal CORT levels (Herman et al., 2001). Brain aging has been construed as being conditioned by an excessive plasma GC secretion leading to damages on brain areas, such as hypothalamus or hippocampus, involved in the control of the activity of the HPA axis (Cameron and Gould, 1994; Lupien et al., 1998; Yau and Seckl, 2012). More recently, an increase in HPA axis activity was shown in vitamin A deficient rats LOU/C, exhibiting retinoid hyposignaling pathway, leading to elevated total plasma CORT level in basal and stress conditions, which is restored to control level by RA treatment (Arvy et al., 2013). However, contrary to this result, it has been shown that chronic RA treatment with high doses $(2 \mathrm{mg} / \mathrm{kg})$ induced a hyperactivation of HPA axis along with an increased basal plasma CORT levels in young rats (Cai et al., 2010). This discrepancy may be related to differences in treatment used (duration of RA injections, doses) and nutritional status (vitamin A deficient rats vs control rats). Moreover, an interesting recent study, has proposed that excessive RA treatment could induce hyperactivation of HPA axis leading to hypersecretion of plasma CORT through an increased hypothalamic expression of RAR $\alpha$ and a deficient negative feedback at the level of hypothalamic GR expression (Hu et al., 2013). In our present study, elevated expression of RAR $\alpha$ would also be deleterious and associated with an alteration in HPA axis. We can propose that our more physiologic short-term RA treatment $(150 \mu \mathrm{g} / \mathrm{kg})$ would lead to a normalization of HPA axis activity in middleaged mice probably via a regulation of hippocampal RARs and GRs levels. However, the precise molecular mechanism by which RA and GCs signaling interacts, awaits future study. Thus, altogether these data suggested that vitamin A status would be an important nutritional factor to take into account in the modulation of the CORT at systemic levels which probably would impact on hippocampal availability of CORT (Yau and Seckl, 2012).

\section{DOES RETINOIC ACID TREATMENT ACT ON HIPPOCAMPAL PLASTICITY AND FUNCTIONS VIA GLUCOCORTICOIDS?}

In the present study, we show that RA treatment has beneficial effects on hippocampal plasticity and functions at middle-age that probably via the modulation of intrahippocampal CORT levels. This hypothesis is also supported by the results of Tronche et al.'s (2010) study showing that the stress-induced hippocampal CORT levels in middle-aged mice were of greater magnitude as compared to young mice, and that a metyrapone (an inhibitor of CORT synthesis) injection before stress blocked both the stressinduced hippocampal CORT rise and associated memory retrieval impairment. GCs can promote behavioral adaptation, regulating (either enhancing or impairing) several memory processes (Joels, 2008). For example, stress can enhance the consolidation of spatial and emotional memories, but it can also impair their retrieval (de Quervain et al., 1998; Sandi and Pinelo-Nava, 2007). Thus, insofar as it has been shown that the effectiveness of learning throughout a continuum of stress and/or CORT levels generally follows an inverted U-shaped function (Salehi et al., 2010), we may hypothesize therefore that RA treatment could normalize stress levels in middle-aged mice during CSD task. Interestingly this hypothesis fits well with a previous study from our group having shown that the administration of diazepam inhibited the stress-induced increase of hippocampal CORT levels and in parallel, restored memory performance in the CSD task (Beracochea et al., 2011). Finally, a recent study has found a decrease in hippocampal PSD-95 protein levels after chronic CORT exposure (Cohen et al., 2011). Thus, PSD-95 seems to be a good plasticityrelated RA and GCs target genes that could be involved, at least in part, in the positive effects of RA treatment on hippocampal functions.

\section{CONCLUSION}

The present study provides breakthrough evidence that RA treatment can decrease and delay the stress-induced intrahippocampal CORT rise in middle-aged mice. Moreover, correlations between vitamin A status evaluated by the hippocampal expression of retinoid receptors and CORT levels in the hippocampus have been evidenced. Interestingly, our data suggest that the improvement of memory and hippocampal plasticity in RAtreated mice could result from a decreased hippocampal CORT rise but future investigations are needed to establish a clearcut causal link. Since vitamin A metabolism alterations occur during aging, our results are of prime importance and further substantiate the view that maintaining a normal vitamin A status in seniors would be crucial to prevent age-related cognitive impairments.

\section{ACKNOWLEDGMENTS}

The authors would like to thank Dominique Panzeri, Nathalie Argenta, and Jennifer Huard for animal care. We also are grateful to Serge Alfos for technical contribution and to Dr Frances ASH (ashberac@free.fr) for language assistance. This work has been supported by the Région Aquitaine and CNRS. 


\section{REFERENCES}

Arvy, N., Hamiani, R., Richard, E., Moisan, M. P., and Pallet, V. (2013). Vitamin A regulates HPA axis status in LOU/C rats. J. Endocrinol. 219, 21-27. doi: 10.1530/JOE-13-0062

Aubry, E. M., and Odermatt, A. (2009). Retinoic acid reduces glucocorticoid sensitivity in $\mathrm{C} 2 \mathrm{C} 12$ myotubes by decreasing 11 beta-hydroxysteroid dehydrogenase type 1 and glucocorticoid receptor activities. Endocrinology 150, 2700-2708. doi: 10.1210/en.2008-1618

Azais-Braesco, V., Moriniere, C., Guesne, B., Partier, A., Bellenand, P., Baguelin, D., et al. (1995). Vitamin A status in the institutionalized elderly. Critical analysis of four evaluation criteria: dietary vitamin A intake, serum retinol, relative doseresponse test (RDR) and impression cytology with transfer (ICT). Int. J. Vitam. Nutr. Res. 65, 151-161.

Beique, J. C., Lin, D. T., Kang, M. G., Aizawa, H., Takamiya, K., and Huganir, R. L. (2006). Synapse-specific regulation of AMPA receptor function by PSD-95. Proc Natl. Acad. Sci. U.S.A. 103, 19535-19540. doi: 10.1073/pnas.0608492103

Beracochea, D., Boucard, A., Trocme-Thibierge, C., and Morain, P. (2008a). Improvement of contextual memory by S 24795 in aged mice: comparison with memantine. Psychopharmacology (Berl.) 196, 555-564. doi: 10.1007/s00213-0070987-5

Beracochea, D., Liscia, P., Tronche, C., Chauveau, F., Jouanin, J. C., and Pierard, C. (2008b). Stress modulation of the memory retrograde-enhancing effects of the awakening drug modafinil in mice. Psychopharmacology (Berl.) 196, 1-13. doi: 10.1007/s00213-007-0915-8

Beracochea, D., Tronche, C., Coutan, M., Dorey, R., Chauveau, F., and Pierard, C. (2011). Interaction between diazepam and hippocampal corticosterone after acute stress: impact on memory in middle-aged mice. Front. Behav. Neurosci. 5:14. doi: 10.3389/fnbeh.2011.00014

Bonnet, E., Touyarot, K., Alfos, S., Pallet, V., Higueret, P., and Abrous, D. N. (2008). Retinoic acid restores adult hippocampal neurogenesis and reverses spatial memory deficit in vitamin A deprived rats. PLoS ONE 3:e3487. doi: 10.1371/journal.pone.0003487

Born, J., Ditschuneit, I., Schreiber, M., Dodt, C., and Fehm, H. L. (1995). Effects of age and gender on pituitary-adrenocortical responsiveness in humans. Eur. J. Endocrinol. 132, 705-711. doi: 10.1530/eje.0.1320705

Brossaud, J., Roumes, H., Moisan, M. P., Pallet, V., Redonnet, A., and Corcuff, J. B. (2013). Retinoids and glucocorticoids target common genes in hippocampal HT22 cells. J. Neurochem. 125, 518-531. doi: 10.1111/jnc.12192

Cai, L., Yan, X. B., Chen, X. N., Meng, Q. Y., and Zhou, J. N. (2010). Chronic all-trans retinoic acid administration induced hyperactivity of HPA axis and behavioral changes in young rats. Eur. Neuropsychopharmacol. 20, 839-847. doi: 10.1016/j.euroneuro.2010.06.019

Cameron, H. A., and Gould, E. (1994). Adult neurogenesis is regulated by adrenal steroids in the dentate gyrus. Neuroscience 61, 203-209. doi: 10.1016/03064522(94)90224-0

Carlisle, H. J., Fink, A. E., Grant, S. G., and O’Dell, T. J. (2008). Opposing effects of PSD-93 and PSD-95 on long-term potentiation and spike timing-dependent plasticity. J. Physiol. 586, 5885-5900. doi: 10.1113/jphysiol.2008.163469

Celerier, A., Pierard, C., Rachbauer, D., Sarrieau, A., and Beracochea, D. (2004) Contextual and serial discriminations: a new learning paradigm to assess simultaneously the effects of acute stress on retrieval of flexible or stable information in mice. Learn. Mem. 11, 196-204. doi: 10.1101/lm.65604

Chauveau, F., Pierard, C., Corio, M., Celerier, A., Christophe, T., Vouimba, R. M., et al. (2009a). Mediodorsal thalamic lesions block the stress-induced inversion of serial memory retrieval pattern in mice. Behav. Brain Res. 203, 270-278. doi: 10.1016/j.bbr.2009.05.014

Chauveau, F., Pierard, C., Tronche, C., Coutan, M., Drouet, I., Liscia, P., et al. (2009b). The hippocampus and prefrontal cortex are differentially involved in serial memory retrieval in non-stress and stress conditions. Neurobiol. Learn. Mem. 91, 447-455. doi: 10.1016/j.nlm.2008.12.003

Chauveau, F., Tronche, C., Pierard, C., Liscia, P., Drouet, I., Coutan, M., et al. (2010). Rapid stress-induced corticosterone rise in the hippocampus reverses serial memory retrieval pattern. Hippocampus 20, 196-207. doi: 10.1002/hipo. 20605

Chiang, M. Y., Misner, D., Kempermann, G., Schikorski, T., Giguere, V., Sucov, H. M., et al. (1998). An essential role for retinoid receptors RARbeta and RXRgamma in long-term potentiation and depression. Neuron 21, 1353-1361. doi: 10.1016/S0896-6273(00)80654-6
Cocco, S., Diaz, G., Stancampiano, R., Diana, A., Carta, M., Curreli, R., et al. (2002). Vitamin A deficiency produces spatial learning and memory impairment in rats. Neuroscience 115, 475-482. doi: 10.1016/S0306-4522(02)00423-2

Cohen, J. W., Louneva, N., Han, L. Y., Hodes, G. E., Wilson, R. S., Bennett, D. A., et al. (2011). Chronic corticosterone exposure alters postsynaptic protein levels of PSD-95, NR1, and synaptopodin in the mouse brain. Synapse 65, 763-770. doi: 10.1002/syn.20900

Delint-Ramirez, I., Salcedo-Tello, P., and Bermudez-Rattoni, F. (2008). Spatial memory formation induces recruitment of NMDA receptor and PSD-95 to synaptic lipid rafts. J. Neurochem. 106, 1658-1668. doi: 10.1111/j.1471-4159.2008.05523.x de Quervain, D. J., Roozendaal, B., and Mcgaugh, J. L. (1998). Stress and glucocorticoids impair retrieval of long-term spatial memory. Nature 394, 787-790. doi: $10.1038 / 29542$

Drapeau, E., Mayo, W., Aurousseau, C., Le Moal, M., Piazza, P. V., and Abrous, D. N. (2003). Spatial memory performances of aged rats in the water maze predict levels of hippocampal neurogenesis. Proc. Natl. Acad. Sci. U.S.A. 100, 14385-14390. doi: 10.1073/pnas. 2334169100

Drapeau, E., Montaron, M. F., Aguerre, S., and Abrous, D. N. (2007). Learninginduced survival of new neurons depends on the cognitive status of aged rats. J. Neurosci. 27, 6037-6044. doi: 10.1523/JNEUROSCI.1031-07.2007

Dyall, S. C., Michael, G. J., and Michael-Titus, A. T. (2010). Omega-3 fatty acids reverse age-related decreases in nuclear receptors and increase neurogenesis in old rats. J. Neurosci. Res. 88, 2091-2102. doi: 10.1002/jnr.22390

Enderlin, V., Pallet, V., Alfos, S., Dargelos, E., Jaffard, R., Garcin, H., et al. (1997). Age-related decreases in mRNA for brain nuclear receptors and target genes are reversed by retinoic acid treatment. Neurosci. Lett. 229, 125-129. doi: 10.1016/S0304-3940(97)00424-2

Etchamendy, N., Enderlin, V., Marighetto, A., Pallet, V., Higueret, P., and Jaffard, R. (2003). Vitamin A deficiency and relational memory deficit in adult mice: relationships with changes in brain retinoid signalling. Behav. Brain Res. 145, 37-49. doi: 10.1016/S0166-4328(03)00099-8

Etchamendy, N., Enderlin, V., Marighetto, A., Vouimba, R. M., Pallet, V., Jaffard, R., et al. (2001). Alleviation of a selective age-related relational memory deficit in mice by pharmacologically induced normalization of brain retinoid signaling. $J$. Neurosci. 21, 6423-6429.

Feart, C., Mingaud, F., Enderlin, V., Husson, M., Alfos, S., Higueret, P., et al. (2005). Differential effect of retinoic acid and triiodothyronine on the agerelated hypo-expression of neurogranin in rat. Neurobiol. Aging 26, 729-738. doi: 10.1016/j.neurobiolaging.2004.06.004

Frick, K. M., Baxter, M. G., Markowska, A. L., Olton, D. S., and Price, D. L. (1995). Age-related spatial reference and working memory deficits assessed in the water maze. Neurobiol. Aging 16, 149-160. doi: 10.1016/0197-4580(94)00155-3

Herman, J. P., Larson, B. R., Speert, D. B., and Seasholtz, A. F. (2001). Hypothalamopituitary-adrenocortical dysregulation in aging F344/Brown-Norway F1 hybrid rats. Neurobiol. Aging 22, 323-332. doi: 10.1016/S0197-4580(00)00242-6

Holmes, M. C., Carter, R. N., Noble, J., Chitnis, S., Dutia, A., Paterson, J. M., et al. (2010). 11beta-hydroxysteroid dehydrogenase type 1 expression is increased in the aged mouse hippocampus and parietal cortex and causes memory impairments. J. Neurosci. 30, 6916-6920. doi: 10.1523/JNEUROSCI.0731-10.2010

Holmes, M. C., Yau, J. L., Kotelevtsev, Y., Mullins, J. J., and Seckl, J. R. (2003). 11 Beta-hydroxysteroid dehydrogenases in the brain: two enzymes two roles. Ann. N. Y. Acad. Sci. 1007, 357-366. doi: 10.1196/annals.1286.035

Hu, P., Liu, J., Zhao, J., Qi, X. R., Qi, C. C., Lucassen, P. J., et al. (2013). All-trans retinoic acid-induced hypothalamus-pituitary-adrenal hyperactivity involves glucocorticoid receptor dysregulation. Transl. Psychiatry 3, e336. doi: 10.1038/tp.2013.98

Joels, M. (2008). Functional actions of corticosteroids in the hippocampus. Eur. J. Pharmacol. 583, 312-321. doi: 10.1016/j.ejphar.2007.11.064

Kaczorowski, C. C., and Disterhoft, J. F. (2009). Memory deficits are associated with impaired ability to modulate neuronal excitability in middle-aged mice. Learn. Mem. 16, 362-366. doi: 10.1101/lm.1365609

Kadish, I., Thibault, O., Blalock, E. M., Chen, K. C., Gant, J. C., Porter, N. M., et al. (2009). Hippocampal and cognitive aging across the lifespan: a bioenergetic shift precedes and increased cholesterol trafficking parallels memory impairment. J. Neurosci. 29, 1805-1816. doi: 10.1523/JNEUROSCI.459908.2009

Lane, M. A., and Bailey, S. J. (2005). Role of retinoid signalling in the adult brain. Prog. Neurobiol. 75, 275-293. doi: 10.1016/j.pneurobio.2005.03.002 
Lupien, S. J., De Leon, M., De Santi, S., Convit, A., Tarshish, C., Nair, N. P., et al. (1998). Cortisol levels during human aging predict hippocampal atrophy and memory deficits. Nat. Neurosci. 1, 69-73. doi: 10.1038/271

Marill, J., Idres, N., Capron, C. C., Nguyen, E., and Chabot, G. G. (2003). Retinoic acid metabolism and mechanism of action: a review. Curr. Drug Metab. 4, 1-10. doi: $10.2174 / 1389200033336900$

Markowska, A. L., and Breckler, S. J. (1999). Behavioral biomarkers of aging: illustration of a multivariate approach for detecting age-related behavioral changes. J. Gerontol. A Biol. Sci. Med. Sci. 54, B549-B566. doi: 10.1093/gerona/54.12.B549

McCaffery, P., Zhang, J., and Crandall, J. E. (2006). Retinoic acid signaling and function in the adult hippocampus. J. Neurobiol. 66, 780-791. doi: 10.1002/neu.20237

Migaud, M., Charlesworth, P., Dempster, M., Webster, L. C., Watabe, A. M., Makhinson, M., et al. (1998). Enhanced long-term potentiation and impaired learning in mice with mutant postsynaptic density-95 protein. Nature 396, 433-439. doi: $10.1038 / 24790$

Mingaud, F., Mormede, C., Etchamendy, N., Mons, N., Niedergang, B., Wietrzych, M., et al. (2008). Retinoid hyposignaling contributes to aging-related decline in hippocampal function in short-term/working memory organization and longterm declarative memory encoding in mice. J. Neurosci. 28, 279-291. doi: 10.1523/JNEUROSCI.4065-07.2008

Mizoguchi, K., Ikeda, R., Shoji, H., Tanaka, Y., Maruyama, W., and Tabira, T. (2009). Aging attenuates glucocorticoid negative feedback in rat brain. Neuroscience 159, 259-270. doi: 10.1016/j.neuroscience.2008.12.020

Nyffeler, M., Zhang, W. N., Feldon, J., and Knuesel, I. (2007). Differential expression of PSD proteins in age-related spatial learning impairments. Neurobiol. Aging 28 143-155. doi: 10.1016/j.neurobiolaging.2005.11.003

Oitzl, M. S., and de Kloet, E. R. (1992). Selective corticosteroid antagonists modulate specific aspects of spatial orientation learning. Behav. Neurosci. 106, 62-71. doi: 10.1037/0735-7044.106.1.62

Olson, C. R., and Mello, C. V. (2010). Significance of vitamin A to brain function, behavior and learning. Mol. Nutr. Food Res. 54, 489-495. doi: 10.1002/mnfr.200900246

Paez-Pereda, M., Kovalovsky, D., Hopfner, U., Theodoropoulou, M., Pagotto, U., Uhl, E., et al. (2001). Retinoic acid prevents experimental Cushing syndrome. J. Clin. Invest. 108, 1123-1131. doi: 10.1172/JCI11098

Paxinos, G., and Franklin, K. B. J. (2001). The Mouse Brain in Stereotaxic Coordinates, 2nd Edn. San Diego: Academic Press.

Penniston, K. L., and Tanumihardjo, S. A. (2006). The acute and chronic toxic effects of vitamin A. Am. J. Clin. Nutr. 83, 191-201.

Pepeu, G. (2004). Mild cognitive impairment: animal models. Dialogues Clin. Neurosci. 6, 369-377.

Pierard, C., Tronche, C., Liscia, P., Chauveau, F., and Beracochea, D. (2009). Combined effects of acute stress and amphetamine on serial memory retrieval pattern in mice. Psychopharmacology (Berl.) 203, 463-473. doi: 10.1007/s00213-0081391-5

Sakamuri, V. P., Ananthathmakula, P., Veettil, G. N., and Ayyalasomayajula, V. (2011). Vitamin A decreases pre-receptor amplification of glucocorticoids in obesity: study on the effect of vitamin A on 11beta-hydroxysteroid dehydrogenase type 1 activity in liver and visceral fat of WNIN/Ob obese rats. Nutr. J. 10, 70. doi: 10.1186/1475-2891-10-70

Salehi, B., Cordero, M. I., and Sandi, C. (2010). Learning under stress: the invertedU-shape function revisited. Learn. Mem. 17, 522-530. doi: 10.1101/lm.1914110
Sandi, C., and Pinelo-Nava, M. T. (2007). Stress and memory: behavioral effects and neurobiological mechanisms. Neural Plast. 2007, 78970. doi: 10.1155/2007/78970

Seckl, J. R. (1997). 1lbeta-Hydroxysteroid dehydrogenase in the brain: a novel regulator of glucocorticoid action? Front. Neuroendocrinol. 18, 49-99. doi: 10.1006/frne.1996.0143

Touyarot, K., Bonhomme, D., Roux, P., Alfos, S., Lafenetre, P., Richard, E., etal. (2013). A mid-life vitamin A supplementation prevents agerelated spatial memory deficits and hippocampal neurogenesis alterations through CRABP-I. PLOS ONE 8:e72101. doi: 10.1371/journal.pone.00 72101

Tronche, C., Pierard, C., Coutan, M., Chauveau, F., Liscia, P., and Beracochea, D. (2010). Increased stress-induced intra-hippocampus corticosterone rise associated with memory impairments in middle-aged mice. Neurobiol. Learn. Mem. 93, 343-351. doi: 10.1016/j.nlm.2009.11.009

VanGuilder, H. D., Farley, J. A., Yan, H., Van Kirk, C. A., Mitschelen, M., Sonntag, W. E., et al. (2011). Hippocampal dysregulation of synaptic plasticity-associated proteins with age-related cognitive decline. Neurobiol. Dis. 43, 201-212. doi: 10.1016/j.nbd.2011.03.012

Vickers, C. A., Stephens, B., Bowen, J., Arbuthnott, G. W., Grant, S. G., and Ingham, C. A. (2006). Neurone specific regulation of dendritic spines in vivo by post synaptic density 95 protein (PSD-95). Brain Res. 1090, 89-98. doi: 10.1016/j.brainres.2006.03.075

Wietrzych, M., Meziane, H., Sutter, A., Ghyselinck, N., Chapman, P. F., Chambon, P., et al. (2005). Working memory deficits in retinoid X receptor gamma-deficient mice. Learn. Mem. 12, 318-326. doi: 10.1101/lm.89805

Yau, J. L., Noble, J., Kenyon, C. J., Hibberd, C., Kotelevtsev, Y., Mullins, J. J., et al. (2001). Lack of tissue glucocorticoid reactivation in 11beta-hydroxysteroid dehydrogenase type 1 knockout mice ameliorates age-related learning impairments. Proc. Natl. Acad. Sci. U.S.A. 98, 4716-4721. doi: 10.1073/pnas.0715 62698

Yau, J. L., and Seckl, J. R. (2012). Local amplification of glucocorticoids in the aging brain and impaired spatial memory. Front. Aging Neurosci. 4:24. doi: 10.3389/fnagi.2012.00024

Conflict of Interest Statement: The authors declare that the research was conducted in the absence of any commercial or financial relationships that could be construed as a potential conflict of interest.

Received: 07 November 2013; accepted: 10 January 2014; published online: 07 February 2014.

Citation: Bonhomme D, Pallet V, Dominguez G, Servant L, Henkous N, Lafenêtre P, Higueret P, Béracochéa D and Touyarot $K$ (2014) Retinoic acid modulates intrahippocampal levels of corticosterone in middle-aged mice: consequences on hippocampal plasticity and contextual memory. Front. Aging Neurosci. 6:6. doi: 10.3389/fnagi.2014.00006

This article was submitted to the journal Frontiers in Aging Neuroscience.

Copyright (C) 2014 Bonhomme, Pallet, Dominguez, Servant, Henkous, Lafenêtre, Higueret, Béracochéa and Touyarot. This is an open-access article distributed under the terms of the Creative Commons Attribution License (CC BY). The use, distribution or reproduction in other forums is permitted, provided the original author(s) or licensor are credited and that the original publication in this journal is cited, in accordance with accepted academic practice. No use, distribution or reproduction is permitted which does not comply with these terms. 